Original Research Paper

\title{
Socio-Economic Losses of Small Fishermen after Lobster Seeding Banning Policy (Case Study in Batu Nampar Selatan Village, East Lombok Regency)
}

\author{
Syarif Husni ${ }^{1 *}$, M. Yusuf ${ }^{1}$, Muhammad Nursan ${ }^{1}$, Aeko Fria Utama FR ${ }^{1}$ \\ ${ }^{1}$ Program Studi Agribisnis Fakultas Pertanian Universitas Mataram, Indonesia
}

\author{
Article History \\ Received : January $06^{\text {th }}, 2021$ \\ Revised : January $10^{\text {th }}, 2021$ \\ Accepted : January $18^{\text {th }}, 2021$ \\ Published : January $23^{\text {th }}, 2021$ \\ *Corresponding Author: \\ Syarif Husni, \\ Program Studi Agribisnis \\ Fakultas Pertanian Universitas \\ Mataram, Indonesia \\ Email: \\ syarifhusni1964@gmail.com
}

\begin{abstract}
The objectives of this study are: 1) to find out the perceptions of small fishermen about PERMEN KP No.1 / 2015 in conjunction with Minister of Marine Affairs and Fisheries Regulation No.56 / 2016, 2) to calculate the social losses of small fishermen after the prohibition policy on the prohibition of fishing for lobster seeds, 3) to calculate the economic losses of small fishermen after lobster seed fishing prohibition policy. This research uses descriptive methods and case studies. Apart from interviews with respondents, it was also conducted using the Focus Group Discussion (FGD) method. The number of respondents was determined as many as 30 people by simple random sampling and the data analysis used consisted of descriptive analysis based on tabulations, and after processing it was presented in tabular form, analysis of people's work days (HKO) and analysis of costs and income. The results showed: 1) The most dominant perception of fishermen is that the existence of the Minister of Marine Affairs and Fisheries Regulation needs to be reviewed and the compensation provided by the government is not in accordance with the conditions of fishermen 2) Social losses for fishermen in terms of employment of $208 \mathrm{HKO} /$ year, and 3) Economic losses, namely the loss of income of small fishermen of 121,329,000 IDR/ year.
\end{abstract}

Keywords: Economic loss, Socio-Economic, Small Fishermen

\section{Pendahuluan}

Indonesia memiliki laut dengan luas 5,8 juta $\mathrm{km} 2,17.508$ pulau dan garis pantai dengan panjang $81.000 \mathrm{~km}$. Propinsi NTB memiliki potensi sumberdaya pesisir dan laut yang cukup besar yang terbentang sepanjang Pulau Lombok dan Sumbawa. Luas perairan laut sekitar $29.159,04 \mathrm{~km} 2$, panjang pantai $2.333 \mathrm{~km}$ dan perairan karang sekitar $3.601 \mathrm{~km}$. Potensi lestari perikanan di NTB 129.863 ton/tahun yang terdiri atas potensi lestari ikan pelagis 55.917,4 ton/tahun dan potensi ikan demersal sebesar 73.945,6 ton/tahun. Kabupaten Lombok Timur yang memiliki wilayah pesisir yang luas di Pulau Lombok dihuni oleh sebagian besar nelayan kecil.

Dengan karunia sumberdaya pesisir dan lautan tersebut, seyogyanya masyarakat mempunyai tingkat kesejahteraan yang mapan, terutama yang bermukim di wilayah pesisir dan kepulauan. Namun sayangnya, justru kelompok nelayan mengalami kesulitan untuk memenuhi kebutuhan dasarnya seperti sandang dan pangan. Masyarakat nelayan dikategorikan sebagai masyarakat miskin dengan indikasi bahwa tingkat perekonomiannya masih lemah karena tingkat pendapatan yang rendah, kualitas hidupnya rendah, kesejahteraan sosial rendah dan hidup dalam kesulitan (Baso, 2013). Hal ini terjadi sejak orde baru sampai masa reformasi sekarang ini yang dibuktikan dengan beberapa faktor yaitu (Mubyarto, Lukman Soetrisno, Michael Dove, 1984 ; Witomo C M dan Nurlaili, 2015) suasana alam yang keras menyebabkan timbulnya ketidakpastian bagi nelayan dalam menjalankan aktivitas sosial ekonomi yang terus menerus dalam menjaga konsistensi produksi hasil tangkapan, kualitas sumber daya manusia nelayan yang rendah, keterbatasan modal usaha menyulitkan nelayan untuk meningkatkan kegiatan ekonominya, pemasaran hasil perikanan yang lebih menguntungkan perantara, dan kebijakan pemerintah yang belum memihak nelayan. Begitu pula masalah kemiskinan nelayan juga seyogyanya disorot atau dipahami 
ke dalam dua kategori, yaitu miskin secara ekonomi dan miskin secara sosial (Satria A, 2003). Oleh karena itu untuk mempertahankan nafkah keberlanjutan bagi nelayan miskin ada beberapa starategi adapatasi yang dilakukan yaitu melakukan diversifikasi kegiatan penangkapan seperti menangkap bibit lobster selain menangkap ikan dan usaha budidaya perikanan (rumput laut), nelayan bekerja di luar perikanan, memanfaatkan anggota keluarga untuk mencari nafkah, membentuk kelompok arisan, menarik simpanan (tabungan), meminjam kepada tetangga, meminjam kepada juragan, meminjam di koperasi, dan menjual asset rumahtangga (Husni S, 2019).

Kebijakan pemerintah melalui Peraturan Menteri Kelautan dan Perikanan (Permen-KP) No 1/2015 jo Permen-KP Nomor 56 Tahun 2016 tentang Larangan Penangkapan dan/atau Pengeluaran Lobster(Panulirus spp), Kepiting(Scyla spp),dan Rajungan (Portunus spp)dari Wilayah Negara Republik Indonesia. Bibit lobster merupakan salah satu komoditi unggulan yang bernilai ekonomis tinggi, sehingga menjadi salah satu target tangkapan nelayan kecil. Harga yang ditawarkan yakni sekitar Rp 14.000-24.000/ekor pada tahun 2014 (Witomo C M dan Nurlaili, 2015).

Agar memperoleh nilai ekonomi besar, penangkap bibit lobster akan tergoda menangkap secara besar-besaran. Jika aktivitas itu tak terkendali, akan terjadi over-eksploitasi dan ancaman kepunahan. Apabila ekspor bibit lobster dibuka seperti sebelum era Permen-KP nomor 56 Tahun 2016, dikhawatirkan kinerja ekonomi lobster dan keberlanjutan sumber daya lobster di alam terancam. Padahal, ketersediaan bibit dan sumber daya lobster di alam jadi kunci utama keberlanjutan ekonomi lobster saat ini dan mendatang (Khudori, 2020)

Aktivitas penangkapan bibit lobster membawa dampak secara sosial dan ekonomi kepada kehidupan nelayan kecil, namun secara ekologi banyak perkiraan akan terjadi penurunan stok bibit lobster akibat tingginya effort, karena faktor ekonomi yang menguntungkan. Oleh karena itu pemerintah mengeluarkan peraturan Permen-KP No.1/2015 jo Permen-KP No.56/2016. Dampak dari kebijakan ini mempengaruhi kondisi kehidupan nelayan kecil baik secara sosial maupun ekonomi. Oleh karena itu perlu dilakukan penelitian "Kerugian Sosial Ekonomi Nelayan Kecil Pasca Kebijakan
Larangan Penangkapan Bibit Lobster (Studi Kasus di Desa Batu Nampar Selatan Kabupaten Lombok Timur)".

Penelitian ini bertujuan : 1) mengetahui persepsi nelayan kecil tentang Permen-KP No.1/2015 jo Permen-KP No.56/2016, 2) menghitung kerugian sosial nelayan kecil pasca kebijakan larangan penangkapan bibit lobster, dan 3) menghitung kerugian ekonomi nelayan kecil pasca kebijakan larangan penangkapan bibit lobster

\section{Bahan dan Metode}

\section{Metode dan Teknik Penelitian}

Penelitian ini menggunakan metode deskriptif, yaitu metode yang bertujuan untuk memcahkan masalah yang ada pada saat sekarang dengan cara mengumpulkan, menyusun, menganalisa dan mengintepretasikan data, kemudian menarik kesimpulan dan menyalin dalam bentuk laporan yang sistematis mengenai objek yang diteliti. Pengumpulan data menggunakan teknik survey, yaitu wawancara langsung dengan responden dengan berpedoman pada daftar pertanyaan yang dibuat terlebih dahulu. Data yang dikumpulkan adalah data tahun 2014 sebelum Permen-KP mulai diberlakukan. Selain wawancara dengan responden juga dilakukan dengan metode Focus Group Disccussion (FGD) (Nazir, 1998)

Penelitian ini menggunakan studi kasus, yaitu metode penelitian yang lebih mendalam selama kurun waktu tertentu. Penentuan Desa Batu Nampar Selatan sebagai lokasi penelitian didasarkan beberapa karakteristik yang unik yaitu jumlah nelayan kecil yang pernah menangkap bibit lobster terbanyak dan melakukan usaha budidaya lobster melalui sistem KJA. Jumlah responden ditetapkan sebanyak 30 orang secara Simple Random Sampling. Penentuan tokoh masyarakat peserta FGD dilakukan dengan teknik informan's rating

\section{Analisis Data}

a. Persepsi nelayan kecil tentang Permen-KP No1/2015 jo Permen-KP No 56/2016 diukur dari pengamatan pengalaman responden menyangkut keberadaan Permen KP tersebut. Obyek persepsi yang dinilai dalam penelitian ini adalah: (a) persepsi keberadaan Pemen KP, (b) persepsi terhadap ekonomi dan kesempatan kerja, 
Husni, S. et al. (2021). Jurnal Biologi Tropis, 21 (1): 112 - 119 DOI: http://dx.doi.org/10.29303/jbt.v21i1.2398

(c) persepsi terhadap komunikasi publik oleh pemerintah, dan (d) persepsi terhadap program pemerintah untuk kompensasi bagi nelayan kecil pasca larangan penangkapan bibit lobster. Data yang diperoleh dianalisis secara deskriptif berbasiskan tabulasi, dan setelah diolah kemudian disajikan dalam bentuk tabel.

b. Kerugian sosial nelayan kecil (penyerapan tenaga kerja) pasca larangan penangkapan bibit lobster dihitung dalam satuan hari kerja orang (HKO) dengan rumus:

(t.h.j/7)

$\mathrm{t}=$ jumlah tenaga kerja (orang)

$\mathrm{h}=$ jumlah hari kerja (hari)

$\mathrm{j}=$ jumlah jam kerja (jam)

c. Kerugian ekonomi (pendapatan) nelayan kecil pasca larangan penangkapan bibit lobster dihitung:

$\mathrm{PNK}=\mathrm{NPNK}-\mathrm{BPNK}$
PNK = pendapatan nelayan kecil

(Rp/tahun)

$\mathrm{NPNK}=$ nilai produksi (Rp/tahun)

$\mathrm{BPNK}=$ Biaya produksi (Rp/tahun)

\section{Hasil dan Pembahasan}

\section{Persepsi Nelayan}

Rahmat (2005) mengemukakan bahwa persepsi adalah pengalaman tentang objek, peristiwa, atau hubungan-hubungan yang diperoleh dengan menyimpulkan informasi dan menafsirkan pesan. Dengan perkataan lain persepsi adalah memberikan makna stimuli inderawi (sensory stimuli) dimana setiap orang atau masyarakat akan mempunyai persepsi yang berbeda-beda tergantung pada stimuli inderawi masing-masing.

Sebaran persepsi nelayan tentang PermenKP d ditampilkan pada Tebel 1 berikut.

Tabel 1. Sebaran nelayan berdasarkan persepsi terhadap keberadaan Permen-KP No 1/2015 jo Permen-KP No.56/2016 di Desa Batu Nampar Selatan

\begin{tabular}{|l|l|c|c|}
\hline No & \multicolumn{1}{|c|}{ Persepsi } & Frekuensi & Persen (\%) \\
\hline 1 & $\begin{array}{l}\text { Permen KP membatasi nelayan } \\
\text { kecil dalam menangkap bibit } \\
\text { lobster }\end{array}$ & 25 & 83,33 \\
\hline 2 & $\begin{array}{l}\text { Permen KP untuk menjaga stok } \\
\text { sumberdaya lobster }\end{array}$ & 5 & 6,77 \\
\hline
\end{tabular}

Sumber: data primer diolah

Persepsi nelayan tentang keberadaan Permen KP tersebut yaitu sangat memberatkan dalam peningkatan kehidupan ekonomi yang selama ini ditopang sebagian besar pendapatan dari penangkapan bibit lobster. Oleh karena itu sebagaian besar nelayan $(83,33 \%)$ menolak adanya larangan penangkapan bibit lobster. Hal yang sama juga dari hasil penelitian Furqan, Nurani, Wiyono dan Soeboer (2017) ditemukan kendala terkait implementasi kebijakan Permen KP No 1/2015 jo Permen KP No 56/2016 nelayan merasa bahwa penangkapan bibit lobster tidak mengganggu keberlanjutan lobster, sehingga nelayan menolak kebijakan pelarangan penangkapan bibit lobster.

Adanya Permen-KP menyebakan kehilangan pendapatan nelayan yang cukup besar, sehingga berdampak terhadap kebutuhan rumah tangga. Akibat peraturan tersebut nelayan di Pulau Lombok melakukan demonstrasi ke pemerintahan daerah, propinsi sampai pemerintah pusat. Sementara itu hanya 6,77\% responden yang memiliki persepsi bahwa Permen-KP tersebut untuk melindungi keberadaan bibit lobster dari kepunahan dan mengancam kelestarian habitat sumberdaya, sehingga perlu ada perlindungan.

Dari sisi sosial ekonomi keberadaan Permen-KP tersebut berdampak terhadap menurunnya pendapatan dan kesempatan kesempatan kerja nelayan. Walaupun nelayan bisa memperoleh pendapatan dari hasil tangkapan ikan, namun tidak mencukupi untuk memenuhi kebutuhan rumah tangga sehari-hari. Penurunan pendapatan nalayan sangat signifikan akibat larangan yang diberlakukan oleh pemerintah. Persepsi responden atas larangan tersebut seluruhnya menyatakan terjadi penurunan pendapatan dan kesempatan kerja seperti disajikan pada Tabel 2. 
Husni, S. et al. (2021). Jurnal Biologi Tropis, 21 (1): 112 - 119

DOI: http://dx.doi.org/10.29303/jbt.v21i1.2398

Tabel 2. Sebaran nelayan berdasarkan persepsi sosial ekonomi terhadap Permen-KP No1/2015 jo Permen-KP No 56/2016 di Desa Batu Nampar Selatan

\begin{tabular}{|l|l|c|c|}
\hline No & \multicolumn{1}{|c|}{ Persepsi } & Frekuensi & Persen (\%) \\
\hline 1 & $\begin{array}{l}\text { Larangan penangkapan bibit lobster } \\
\text { mengakibatkan kesempatan kerja dan } \\
\text { pendapatan nelayan menurun }\end{array}$ & 30 & 100,00 \\
\hline 2 & $\begin{array}{l}\text { Larangan penangkapan bibit lobster } \\
\text { tidak berpengaruh terhadap } \\
\text { kesempatan kerja dan pendapatan } \\
\text { nelayan }\end{array}$ & 0 & 0,00 \\
\hline
\end{tabular}

Sumber: data prmer diolah

Selain penurunan pendapatan yang dialami oleh nelayan, pelarangan penangkapan berdampak juga terhadap kesempatan kerja di kalangan nelayan. Jika waktu yang dibutuhkan untuk penangkapan bibit lobster rata-rata per hari 3 jam, yaitu mulai dari pengambilan bibit lobster dari perangkap yang dipasang sehari sebelumnya sampai dengan pembersihan waring dan pemasangan perangkap. Sehingga terjadi kehilangan kesempatan kerja 0,42 HKO per hari atau $153,30 \mathrm{HKO}$ per tahun.

Sementara itu komunikasi publik oleh pemerintah menunjukkan sebanyak 83,33\% mengaku tidak pernah mendapat sosialisasi secara langsung dari pemerintah dan 16,67\% pernah mengikuti sosialisasi yang dilakukan oleh Dinas Kelautan dan Perikanan Kabupaten Lombok Timur sebanyak 2 kali dan hanya diwakili oleh ketua kelompok nelayan seperti ditampilkan pada Tabel 3.

Tabel 3. Sebaran nelayan berdasarkan persepsi sosialisasi Permen Permen KP No 1/2015 jo Permen KP No 56/2016 di Desa Batu Nampar Selatan

\begin{tabular}{|l|l|c|c|}
\hline No & \multicolumn{1}{|c|}{ Persepsi } & Frekuensi & Persen (\%) \\
\hline 1 & $\begin{array}{l}\text { Sosialisasi Permen-KP oleh } \\
\text { pemerintah sudah dilakukan }\end{array}$ & 5 & 16,67 \\
\hline 2 & $\begin{array}{l}\text { Sosialisasi Permen-KP oleh } \\
\text { pemerintah belum pernah dilakukan }\end{array}$ & 25 & 83,33 \\
\hline
\end{tabular}

Sumber: data prmer diolah

Pada Tabel 4 tampak bahwa Program pemerintah untuk kompensasi bagi nelayan sebanyak $100 \%$ menyatakan pemberian kompensasi tidak sesuai harapan, karena yang diberikan bantuan hanya berupa keramba jaring apung (KJA), sedangkan bibit lobster dan pakan lobster ditanggung sendiri oleh nelayan. Pada hal biaya pakan lobster sangat mahal dan tidak

terjangkau dengan kondisi ekonomi yang terpuruk akibat larangan penangkapan bibit lobster. Bantuan yang diberikan oleh pemerintah tidak dapat dimanfaatkan secara optimal oleh nelayan untuk pemeliharaan lobster, sehingga bantuan tersebut terbengkalai dan tidak dimanfaatkan.

Tabel 4. Sebaran nelayan berdasarkan persepsi bantuan kompensasi di Desa Batu Nampar Selatan

\begin{tabular}{|l|l|l|c|}
\hline No & Persepsi & Frekuensi & Persen (\%) \\
\hline 1 & $\begin{array}{l}\text { Kompensasi yang berikan oleh } \\
\text { pemerintah sudah memenuhi harapan }\end{array}$ & 0 & 0,00 \\
\hline 2 & $\begin{array}{l}\text { Kompensasi yang diberikan oleh } \\
\text { pemerintah belum memenuhi harapan }\end{array}$ & 30 & 100,00 \\
\hline
\end{tabular}

Sumber: data primer diolah 
Kerugian Sosial Nelayan Kecil Pasca Pelarangan Penangkapan Bibit Lobster

Kerugian sosial akibat pelarangan penangkapan bibit lobster melalui pendekatan hilangnya kesempatan kerja nelayan yang diukur dari penyerapan tenaga kerja selama setahun ditampilkan pada Tabel 5 berikut.

Persoalan dasar yang dihadapi oleh masyarakat pesisir khususnya nelayan kecil kesempatan kerja yang terbatas terutama di luar sektor perikanan dan kelautan. Keterlibatan seluruh anggota keluarga terutama nelayan dalam mencari nafkah untuk memenuhi kebutuhan rumah tangga menjadi secercah harapan ditengan keterbatasan yang ada. Menurut Hermanto (1986) bahwa setiap nelayan di Muncar dalam kegiatan penangkapan mempunyai jam kerja sekitar 14-20 jam per hari selama 15-25 hari per bulan. Untuk hari-hari tidak melaut mereka gunakan untuk memperbaiki alat tangkap, mesin ataupun perahunya. Sedangkan menurut Purwono (1991) di Puger Jember, nelayan bekerja per minggu rata-rata 4,9 hari dengan rata-rata 9,5 jam per hari. Selebihnya dari waktu tersebut menyatakan menganggur. Dalam satu tahun sebagaian besar waktu nelayan dihabiskan untuk kegiatan penangkapan ikan di laut yaitu pada musim puncak rata-rata 15 trip atau $8 \mathrm{HKO} /$ trip, pada musim sedang $11 \mathrm{jam} /$ trip atau 1,3 HKO. Dalam setahun rata-rata menjalankan kegiatan melaut pada musim puncak sebanyak 48 trip dan pada musim sedang sebanyak 146 trip atau total 306 HKO (Purwanti, 2010).

Tabel 5. Penyerapan tenaga kerja pada aktivitas penangkapan bibit lobster di Desa Batu Nampar Selatan

\begin{tabular}{|l|l|r|r|r|}
\hline No & Jenis kegiatan & $\begin{array}{l}\text { Jumlah } \\
\text { (menit/hari) }\end{array}$ & HKO/ hari & HKO/tahun \\
\hline 1 & Pulang pergi ke keramba & 60 & 0,14 & 54,75 \\
\hline 2 & Pembersihan waring/jaring & 45 & 0,10 & 36,50 \\
\hline 3 & $\begin{array}{l}\text { Pemasangan alat tangkap bibit } \\
\text { lobster (pocong) }\end{array}$ & 45 & 0,10 & 36,50 \\
\hline 4 & Pengambilan bibit lobster & 30 & 0,07 & 25,55 \\
\hline & Jumlah & 180 & 0,42 & 153,30 \\
\hline
\end{tabular}

Sumber: data primer diolah

Ketika terjadi pelarangan penangkapan bibit lobster membatasi aktivitas nelayan sebanyak 0,42 HKO per hari atau 153,30 HKO per tahun. Artinya kesempatan (penyerapaan tenaga kerja) yang hilang sebesar $153 \mathrm{HKO}$ atau 153 hari kerja, sehingga banyak nelayan yang beralih menambah waktu untuk aktivitas penangkapan ikan atau pada kegiatan yang lain. Pada hal Produktivitas kerja dari kegiatan penangkapan ikan lebih rendah dibandingkan dengan aktivitas penangkapan bibit lobster. Produktivitas kerja nelayan dipengaruhi oleh tanggungan keluarga, artinya semakin banyak anggota keluarga akan meningkatkan produktivitas nelayan dan kekuatan penggerak perahu berpengaruh positif serta status nelayan yaitu nelayan juragan memiliki produktivitas yang lebih tinggi bila dibandingkan nelayan pendega (Purwanti P, Kamiso HN dan Tumari J, 1995). Kondisi yang sama terjadi pada nelayan yang melakukan kegiatan usaha budidaya rumput laut dapat menyerap tenaga kerja sebesar 201,14 HKO per tahun (Suparmin, Nurliah dan Husni S, 2016).

\section{Kerugian Ekonomi Nelayan Kecil Pasca} Pelarangan Penangkapan Bibit Lobster

Kerugian pendapatan nelayan adalah hilangnya pendapatan nelayan kecil dari hasil penangkapan bibit lobster akibat diberlakukan pelarangan oleh pemerintah. Untuk menghitung kerugian nelayan kecil per tahun yaitu menggunakan data tahun 2014 yaitu pendapatan nelayan kecil dihitung dari jumlah bibit lobster yang ditangkap dikalikan dengan harga per ekor, kemudian dikurangi dengan biaya produksi (biaya operasional dan biaya tetap)

Biaya produksi merupakan jumlah keseluruhan dari semua biaya operasional dan biaya tetap. Biaya operasional adalah biaya yang besar kecilnya tergantung dari jumlah produksi yang meliputi biaya BBM, oli, dan tenaga kerja 
Husni, S. et al. (2021). Jurnal Biologi Tropis, 21 (1): 112 - 119 DOI: http://dx.doi.org/10.29303/jbt.v21i1.2398

luar keluarga. Sedangkan biaya tetap adalah biaya yang tidak habis dipakai dalam satu kali proses produksi yang meliputi biaya penyusutan alat. Dalam setahun nelayan menangkap bibit lobster sebanyak 360 trip penangkapan. Adapun rincian biaya produksi yang dikeluarkan nelayan per tahun disajikan pada Tabel 6 berikut.

Tabel 6. Biaya produksi penangkapan bibit lobster nelayan kecil di Desa Batu Nampar Selatan

\begin{tabular}{|c|c|c|c|}
\hline No & Jenis Biaya Produksi & Nilai (Rp) & Persen $(\%)$ \\
\hline 1 & Biaya Operasional & & \\
\hline & a. BBM perahu & 7.300 .000 & 37,32 \\
\hline & b. BBM gengset & 9.000 .000 & 46,00 \\
\hline & c. Oli & 300.000 & 1,53 \\
\hline & Sub Total & 16.600 .000 & 84,86 \\
\hline 2 & $\begin{array}{l}\text { Biaya Tetap } \\
\text { a. Penyusutan alat }\end{array}$ & 2.961 .000 & 15,14 \\
\hline & Total Biaya Produksi & 19.561 .000 & 100,00 \\
\hline
\end{tabular}

Sumber: data primer diolah

Biaya yang paling dominan yang dikeluarkan oleh nelayan dalam penangkapan bibit lobster adalah biaya opersional sebesar $84 \%$ dari total biaya produksi. Penggunaan biaya operasional difokuskan pada biaya BBM dan oli untuk perahu dan gengset. Pengeluaran biaya tenaga luar keluarga tidak dilakukan karena kegiatan penangkapan bibit lobster tidak membutuhkan tenaga kerja yang banyak. Penggunaan tenaga kerja dalam keluarga merupakan salah satu karakteristik dari nelayan kecil yang membedakan dengan nelayan komersial.

Biaya tetap dalam hal ini biaya penyusutan alat yang dikeluarkan oleh nelayan sebesar $15,14 \%$ dari biaya produksi. Biaya penyusutan alat keramba terdiri biaya peralatan bambu, waring, rumah jaga, jangkar, tali jangkat, gengset, perahu, sterofoam, dan lampu listrik serta kertas semen (bahasa setempat: pocong).

Pada Tabel 7 tampak menunjukkan hasil tangkapan nelayan rata-rata sebanyak 9.855 ekor terdiri dari bibi lobster mutiara 6.935 ekor dengan harga Rp 14.000 per ekor dan jenis bibit lobster pasir 2.920 ekor, harganya Rp 12.000 per ekor. Setelah dikurangi dengan biaya produksi, diperoleh pendapatan nelayan sebesar $\mathrm{Rp}$ 112.569.000 per tahun. Besar kecilnya pendapatan nelayan dari kegiatan penangkapan juga dipengaruhi jumlah anggota keluarga, pengalaman, musim dan wilayah penangkapan (Maryono, J., Karnan, Santoso D., Husni S., 2012). Begitu pula hasil penelitian Rahim, D R D Hastuti, A Syahma dan Firmansyah (2018) bahwa lama melaut dan ukuran kekuatan mesin tempel berpengaruh positif terhadap pendapatan nelayan tangkap.

Pendapatan nelayan yang tinggi dari penangkapan bibit lobster tersebut menurut Mirwantini C, et al (2015) memberikan dampak yang signifikan terhadap kehidupan sosial ekonomi masyarakat di sekitar perairan Lombok khususnya Lombok Timur dan Lombok Tengah dengan rata-rata penghasilan per hari Rp 600.000 .

Tabel 7. Pendapatan Nelayan Kecil dari penangkapan bibit Lobster di Desa Batu Nampar Selatan

\begin{tabular}{|l|l|c|c|}
\hline No & Komponen & Jumlah (ekor) & Nilai (Rp) \\
\hline 1 & Jenis bibit lobster & & \\
\hline & a. Mutiara & 6.935 & 97.090 .000 \\
\hline & b. Pasir & 2.920 & 35.040 .000 \\
\hline & Jumlah/Nilai produksi & 9.855 & 132.130 .000 \\
\hline 2 & Biaya produksi & & 19.561 .000 \\
\hline 3 & Pendapatan nelayan & & 112.569 .000 \\
\hline
\end{tabular}

Sumber: data primer diolah 
Dengan demikian kerugian nelayan akibat larangan penangkapan bibit lobster sebesar $\mathrm{Rp}$ 112.569.000 per tahun. Hasil penelitian Karnan, Santoso D dan Husni S (2015) pendapatan nelayan dari kegiatan penangkapan ikan di pesisir Kabupaten Lombok Timur tahun 2014 hanya sebesar Rp 41.371.084 per tahun. Pendapatan nelayan dari penangkapan bibit lobster lebih tinggi atau sebesar $272 \%$ jika dibandingkan pendapatan dari aktivitas penangkapan ikan. Bila dibandingkan dengan pendapatan nelayan buruh bahkan lebih rendah lagi yatu Rp 39.247.368/tahun (Abubakar, Husni S, dan Iskandar A, 2020).

Fenomena pelarangan penangkapan bibit lobster tidak hanya dari sisi social dan ekonomi, tetapi berdampak pula terhadap keberlanjutan sumberdaya lobster seperti munculnya kembali bank harian di desa-desa pesisir yang memberikan peminjaman untuk memenuhi kebutuhan sehari dan terjadinya kembali penangkapan tidak ramah lingkungan yang menggunakan kompresor untuk menangkap lobster dewasa ukuran 300 gram (Witomo C M dan Nurlaili, 2015).

\section{Kesimpulan}

Persepsi nelayan dari keberadaan Permen-KP No1/2015 jo Permen-KP No 56/2016 perlu ditinjau kembali dan dicabut, kondisi sosial ekonomi nelayan menurun, sosialisasi yang kurang dan kompensasi yang diberikan oleh pemerintah tidak sesuai dengan harapan nelayan. Kerugian sosial nelayan kecil dalam hal penyerapan tenaga kerja sebesar $153,30 \mathrm{HKO} /$ tahun, dan kerugian ekonomi yaitu hilangnya pendapatan nelayan kecil sebesar $\mathrm{Rp}$ 112.569.000/tahun

\section{Ucapan terima kasih}

Ucapan terima kasih kepada Rektor Unram, Ketua LPPM dan Dekan Fakultas Pertanian Unram atas bantuan biaya penelitian melalui dana PNBP Universitas Mataram tahun 2020.

\section{Refrensi}

Abubakar, Husni S, \& Iskandar A, (2020). Measurement of Food Security in Labor
Fisherment Household in the Coastal Areas of Lombok Island (Case Study in Labuhan Lombok Village, East Lombok District). Jurnal of Civil Engineering and Technology (IJCIET). 11 (03), March 2020, pp 131.

Baso A, (2013). Revitalisasi Pemberdayaan Masyarakat Pesisir Bagi Kesejahteraan Nelayan. Dalam Buku Membangun Sumber Daya Kelautan Indonesia: Gagasan dan Pemikiran Guru Besar Universitas Hasanuddin. IPB Press dan Hasanuddin University Press.

Furqan, Nurani T W, Wiyono E S \& Soeboer D A. (2017). Tingkat Pemahaman Nelayan Terkait dengan Kebijakan Pelarangan Penangkapan Benih Lobster Panilirus spp. di Pelabuhan Ratu. Jurnal Albacore. 1 (3), Oktober 2017. Halaman 297-308.

Hermanto (1986). Analisis Pendapatan dan pencurahan Tenaga kerja Nelayan di Desa Pantai: Studi Kasus di Muncar Banyuwangi. Pusat Penelitian Agroekonomi Badan Penelitian dan Pengembangan Pertanian Jakarta.

Husni S, (2019). Pendapatan Rumah Tangga Nelayan Buruh dan Strategi Adapatasi yang Dilakukan dalam Pemenuhan Kebutuhan Pokok pada Musim Barat (Studi Kasus di Desa Sekotong Barat Kabupaten Lombok Barat). Makalah Seminar Nasional dengan tema Membangun Pertanian Sehat untuk Mendukung Ketahanan Pangan Menuju Sustainable Development Goals di Era Industri 4.0. Fakultas Pertanian Unram. Tanggal 16 November 2019.

Karnan, Santoso D, \& Husni S, (2015). Survei Perikanan Desa Nelayan di Kabupaten Sumbawa Barat dan Lombok Timur Bagian Selatan Nusa Tenggara Barat. Kerjasma LPPM Unram dan PT Newmont Nusa Tenggara (PT NNT).

Khudori (2020). Ekspor benih lobster dan nasib nelayan) (https://www. jawapos.com/opini/24/12/2019/eksporbenih-lobster-dan-nasib-nelayan/ 
Kusnadi (2002). Konflik Sosial Nelayan: Kemiskinan dan Perebutan Sumberdaya Perikanan. LKIS, Yogyakarta.

Maryono J, Karnan, Santoso D, \& Husni S, (2012). Economic Analysis of Traditional Fishery in Western Sumbawa and Eastern Lombok of Nusa Tenggara Barat Province Indonesia. Jurnal Review of Indonesian Economic and Business Studies. 3 (2), November 2012.

Mubyarto, Lukman Soetrisno \& Dove (1984). Nelayan dan Kemiskinan. Sudi Ekonomi Antropologi di Dua Desa Pantai. Rajawali, Jakarta.

Nazir, M. (1988). Metode Penelitian. Ghalia Indonesia. Jakarta

Purwono, G S, (1991). Alokasi Waktu dan Produktivitas Nelayan di Kecamatan Puger Kabupaten Jember, FPS UGM, Yogyakarta. Thesis.

Purwanti P, Kamiso HN \& Tumari J, (1995), Curahan Waktu dan Produktivitas KerjanNelayan di Kabupaten Pasuruan. Jurnal Berkala Penelitian Pasca Sarjana (BPPS) UGM Kelompok IPS dan Humaniora Jilid 8 No 1A. Februari 1995. 126 hal.

Purwanti P, (2010). Model Ekonomi Rumah Tangga Nelayan Skala Kecil dalam
Mencapai Ketahanan Pangan

Universitas Barwijaya Press (UB Press).

Rahim, D R D Hastuti, A Syahma \& Firmansyah, (2018). Pengaruh Melaut, Kekuatan Mesin Tempel dan Karakteristik Responden Terhadap Pendapatan Nelayan Tangkap Tradisional di Kabupaten Takalar. Jurnal Agrisocionomics 2(1): 50-57; Mei 2018.

Rakhmat J, (2005). Psikologi Komunikasi. Bandung. PT. Remaja Rosdakarya

Satria A, (2001), Dinamika Modernisasi Perikanan: Formasi Sosial dan Mobilitas Nelayan. Humaniora Utama Press. 153 hal.

Suparmin, Nurliah, \& Husni S, (2016). Perubahan Perilaku dan Keseimbangan Ekonomi Rumahtangga Nelayan Melalui Model Minapolitan Rumput Laut di Pulau Lombok. Bunga Rampai Iptek Sumberdaya Persisir untuk Pengembangan Blue Economy di Pulau Lombok. Pusat Peneltian dan Pengembangan Sumberdaya Laut dan Pesisir Badan Peneltian dan Pengembangan Kelautan dan Perikanan Kementerian Kelautan dan Perikanan. IPB Press.

Witomo C M \& Nurlaili (2015). Strategi Keberlanjutan Pengelolaan Bibit Lobster di Perairan Lombok. Jurnal Kebijakan Sosial Ekonomi Kelautan dan Perikanan, 5 (1) Tahun 2015. 